\title{
Quantiferon-TB Gold in tube assay for the screening of tuberculosis before and during treatment with tumor necrosis factor alpha antagonists
}

\author{
Gulen Hatemi ${ }^{1}$, Melike Melikoglu ${ }^{1 *}$, Fatma Ozbakir ${ }^{2}$, Koray Tascilar $^{1}$ and Hasan Yazici ${ }^{1}$
}

\begin{abstract}
Introduction: The usefulness of interferon-gamma (IFN- $\gamma$ ) release assays for tuberculosis screening before tumor necrosis factor-alpha (TNF- $\alpha$ ) antagonists and for monitoring during treatment is a contraversial issue. The aims of this study were to determine whether TNF- $\alpha$ antagonists affect the results of the Quantiferon-TB Gold in-tube assay (QTF); to assess how QTF performs in comparison with the tuberculin skin test (TST) in rheumatoid arthritis (RA) patients who are about to start treatment with TNF- $\alpha$ antagonists, RA patients who are not candidates for treatment with TNF- $\alpha$ antagonists, rheumatology patients with confirmed current or past tuberculosis infection, and healthy controls, and to determine the specificity of the QTF test to differentiate leprosy patients, another group of patients infected with mycobacteria.
\end{abstract}

Methods: The 38 RA patients who were prescribed TNF- $\alpha$ antagonists, 40 RA patients who were not considered for TNF- $\alpha$ antagonist use, 30 rheumatology patients with a history or new diagnosis of tuberculosis, 23 leprosy patients, and 41 healthy controls were studied. QTF and TST were done on the same day, and both were repeated after a mean of $3.6 \pm 0.2$ months in patients who used TNF- $\alpha$ antagonists.

Results: Treatment with TNF- $\alpha$ antagonists did not cause a significant change in the QTF or TST positivity rate (34\% versus $42 \% ; P=0.64$; and $24 \%$ versus $37 \% ; P=0.22$ ). Patients with leprosy had a trend for a higher mean IFN- $\gamma$ level $(7.3 \pm 8.0)$ and QTF positivity (61\%) than did the other groups; however, the difference was not significant $(P=0.09$ and $P=0.43)$.

Conclusions: Treatment with TNF- $\alpha$ antagonists does not seem to affect the QTF test to an appreciable degree. The higher IFN- $\gamma$ levels in leprosy patients deserves further attention.

\section{Introduction}

Tuberculosis infection, usually as a reactivation of latent tuberculosis, is an important complication of treatment with tumor necrosis factor-alpha (TNF- $\alpha)$-blocking drugs [1]. Guidelines have been developed in many countries for screening for latent tuberculosis before starting TNF- $\alpha$ antagonists [2-7]. Despite minor differences, they all include a good clinical history, physical

\footnotetext{
* Correspondence: melikoglum@yahoo.com

'Istanbul University, Cerrahpasa Medical School, Department of Internal

Medicine, Division of Rheumatology, Istanbul, Turkey

Full list of author information is available at the end of the article
}

examination, chest radiograph, and the tuberculin skin test (TST) [8].

Interpretation of the TST may be challenging for several reasons, such as false-positive results caused by Bacille Calmette-Guérin (BCG) vaccination and infection with other mycobacteria and false-negative results caused by immunosuppresssion and waning of the TST over time. An increased frequency of negative TST results has been reported in RA patients, especially among those who were eligible for TNF- $\alpha$-antagonist use, probably related to disease severity, which by itself might be a cause of the immunosuppressed state [9]. Other problems with the TST are difficulties in 
standardization of the administration and the reading of the test.

The interferon gamma (IFN- $\gamma$ ) release assays (IGRAs) have emerged as promising alternatives to TST for screening latent tuberculosis. The two types of commercially available IGRAs are the Quantiferon test, which measures antigen-spesific IFN- $\gamma$ released by circulating $\mathrm{T}$ cells in whole blood, and ELISPOT, which measures the presensitized T cells specific to Mycobacterium tuberculosis isolated from peripheral blood mononuclear cells, which release IFN- $\gamma$. The Quantiferon-TB gold test in-tube assay (QTF) is a newer and more practical method. The QTF test is proposed to be more sensitive and more specific than TST because it is not affected by BCG vaccination and infections with other mycobacteria [10]. However, it is hard to interpret the specificity and sensitivity of this test, as is also true for the TST, because no gold standard exists for diagnosing latent tuberculosis. It has been suggested by some that the QTF test may replace TST before starting TNF- $\alpha$ antagonists [11], whereas some propose that it could be used as an adjunct to the TST $[12,13]$. Still others suggested that it is not cost effective and reliable enough in immunosuppressed patients [14,15].

The follow-up of patients who are being treated with TNF- $\alpha$ antagonists for tuberculosis is a further and important problem. The duration of treatment with these agents is usually long, and many of the patients receive TNF- $\alpha$ antagonists for years. Apart from activation of latent tuberculosis, new tuberculosis infections can also become a problem, especially in countries with a high prevalence of tuberculosis. Guidelines are not clear on how to monitor these patients regarding the development of tuberculosis [2-4]. Thus it is important to know how these tests perform in patients receiving TNF- $\alpha$ antagonists.

We previously showed that the TST is not affected by treatment with TNF- $\alpha$ antagonists [9]. However, we did not know whether this was also true for the QTF test. A former impression suggested that the IFN- $\gamma$ response may be reduced in patients who are taking TNF- $\alpha$ antagonists, and caution was recommended when interpreting negative IGRA results in such patients [16].

The specificity of the QTF test for differentiating $M$. tuberculosis from other mycobacteria is another issue that needs further attention. Leprosy is another mycobacterial infection that was endemic until recently in the country where this study was conducted, as well as in other countries where tuberculosis is still endemic. It was shown that the surface proteins ESAT-6 and CFP10 used in the QTF test are also present in M. leprae [17]. Moreover, reactivation of leprosy was reported in three patients who were using TNF- $\alpha$ antagonists
[18-20]. However, the QTF test had not been studied among patients with leprosy.

The aims of the current study were (a) to determine whether TNF- $\alpha$ antagonists affect the QTF test; (b) to determine how the QTF test performs in comparison to the TST in rheumatoid arthritis (RA) patients treated with TNF- $\alpha$ antagonists, RA patients who are not treated with TNF- $\alpha$ antagonists, rheumatology patients who had had proven tuberculosis, and healthy controls; and (c) to assess the QTF test in leprosy patients, another group of patients infected with mycobacteria.

\section{Materials and methods}

Thirty-eight RA patients who were about to start treatment with TNF- $\alpha$ antagonists (TNF-RA): 40 RA patients who had not used and who were not being considered for using TNF- $\alpha$ antagonists (TNF-naive RA), 30 patients with various rheumatologic conditions who had a history or a new diagnosis of culture-positive tuberculosis, 23 patients with leprosy, and 41 healthy controls $(\mathrm{HC})$, who were relatives or friends of patients attending our outpatient rheumatology clinic, were studied. Apart from the rheumatology patients who had had tuberculosis, none of the study subjects had a personal history or a history of contact with tuberculosis. Arms of all study subjects were checked for the presence or absence of Bacille Calmette-Guérin (BCG) scars.

Among the TNF-RA patients, 32 (84\%) of 38 were using methotrexate, six (16\%) of 38 were using sulfasalazine, eight (21\%) of 38 were using hydroxychloroquine, 12 (32\%) of 38 were using leflunomide, and 35 (92\%) of 38 were using prednisolone during the first TST and QTF tests. Among TNF-naive RA patients, 31 (78\%) of 40 were using methotrexate, seven (18\%) of 40 were using sulfasalazine, six (15\%) of 40 were using hydroxychloroquine, eight (20\%) of 40 were using leflunomide, and $33(83 \%)$ of 40 were using prednisolone during the TST and QTF tests. No significant differences were found regarding baseline treatment modalities between the two groups. The TNF- $\alpha$ antagonists that were used were etanercept in 16 patients $(13.6 \pm 0.6$ weeks; range, 12 to 14 ), infliximab in 11 patients (three infusions at weeks 0,2 , and 6 ), and adalimumab in 11 patients (13.5 \pm 0.7 weeks; range, 12 to 14 ).

After informed consent was obtained, blood was collected for the QTF assay, and TST was administered afterward. Quantiferon-TB Gold in-tube (Cellestis Ltd, Victoria, Australia) was used for the QTF assay. One milliliter of blood was drawn for each of the three test tubes. One of these tubes contained three antigens specific for M. tuberculosis (ESAT-6, CFP-10, and TB-7.7). The second tube was the positive control tube and was coated with the T-cell mitogen phytohemagglutinin. The 
third tube was the negative control tube and was coated only with EDTA. The tubes were shaken vigorously and incubated at $37^{\circ} \mathrm{C}$ for 24 hours. Then the tubes were centrifuged, and the supernatant was stored at $-20^{\circ} \mathrm{C}$ until the IFN- $\gamma$ was measured in an enzyme-linked immunosorbent assay (ELISA) reader. The QTF test was interpreted according to instructions of the manufacturer, by subtracting the amount of IFN- $\gamma$ in the negative control tube from that in the M. tuberculosisspecific antigens tube. The level of IFN- $\gamma$ in the negative control tube was subtracted from that in the phytohemagglutinin tube for positive control. For a positive test, all three conditions had to be met: the IFN- $\gamma$ level in the negative-control well (nil) should be $\leq 8.0 \mathrm{IU} / \mathrm{ml}$; the IFN- $\gamma$ level in the well containing M. tuberculosisspecific antigens minus the negative control should be $\geq$ $0.35 \mathrm{IU} / \mathrm{ml}$; and this same level should be $\geq 25 \%$ of nil.

TST was administered by using the Mantoux technique. The forearm was cleaned with alcohol, and $0.5 \mathrm{IU}$ of purified protein derivative (PPD) solution was injected intradermally. The transverse diameter of the induration was measured 48 to 72 hours later by two independant observers. Patients put their arms through a curtain with holes to provide blinding of the observers. The hands were also covered to prevent the observers from recognizing the hand deformities of RA patients.

Patients who were prescribed TNF- $\alpha$ antagonists had two QTF assays and TSTs, one before the administration of the first dose of TNF- $\alpha$ antagonists, and the other when they came for their second prescription, after a mean of $3.6 \pm 0.2$ months. We think that all of our patients had reached steady-state concentrations of TNF- $\alpha$ antagonists by that time, because adalimumab reaches maximum steady-state concentration at $90 \pm 48$ hours, etanercept, at $62 \pm 29$ hours, and no further accumulation of infliximab was observed after the loading dose with infusions at weeks 0,2 , and 6 [21].

Mean TST indurations in each group were compared by using ANOVA. The number of patients with a positive TST and a positive QTF test in each group were compared by using the Kruskal-Wallis test. The same comparisons were made within the group of RA patients who were prescribed TNF- $\alpha$ antagonists, between before- and after-treatment values. The concordance between the TST and QTF tests when positive TST was defined as an induration of $\geq 10 \mathrm{~mm}$ was evaluated by using kappa statistics.

The study was approved by the ethical committee of Istanbul University, Cerrahpasa Medical School.

\section{Results}

Demographic features and QTF and TST results of each group are given in Table 1 . Treatment with TNF- $\alpha$ antagonists did not significantly affect the QTF and the TST results. The frequency of QTF positivity was 34\% before starting TNF- $\alpha$ antagonists and $42 \%$ after $3.6 \pm$ 0.2 months of treatment $(P=0.64)$. After treatment with TNF- $\alpha$ antagonists, the QTF test results did not change in 29 of 38 patients, converted from negative to positive in four of 38 patients, and reverted from positive to negative in three of 38 patiens. The two indeterminate results found before TNF- $\alpha$ antagonists became positive. The mean IFN- $\gamma$ level in the positive-control well increased significantly $(P<0.001)$ after treatment with TNF- $\alpha$ antagonists, whereas the IFN- $\gamma$ level in the tuberculosis-antigen well did not change (Table 2). After treatment with TNF- $\alpha$ antagonists, the TST positivity rate changed from $24 \%$ to $37 \%$ when a positive TST was defined as $\geq 10 \mathrm{~mm}$, and from $26 \%$ to $45 \%$ when defined as $\geq 5 \mathrm{~mm}$. However, the differences were not statistically significant $(P=0.32$ and $P=0.15)$.

Table 1 Demographic features of patients and controls

\begin{tabular}{|c|c|c|c|c|c|c|}
\hline & RA-TNF1 $(n=38)$ & RA-TNF2 $(n=38)$ & $\begin{array}{l}\text { TNF-naive RA } \\
(n=40)\end{array}$ & $\begin{array}{l}\text { TB } \\
(n=30)\end{array}$ & $\begin{array}{l}\text { Leprosy } \\
(n=23)\end{array}$ & $\begin{array}{l}\text { Healthy controls } \\
(n=41)\end{array}$ \\
\hline$F: M$ & $31: 7$ & $31: 7$ & $29: 11$ & $21: 9$ & $7: 16$ & $29: 12$ \\
\hline Mean age (years) & $51.7 \pm 14.2$ & $51.7 \pm 14.2$ & $52.6 \pm 13.5$ & $43.0 \pm 13.4$ & $57.1 \pm 9.6$ & $41.1 \pm 12.1$ \\
\hline BCG scar $(+)$ & 24 & 24 & 25 & 23 & 16 & 27 \\
\hline \multicolumn{7}{|l|}{ QTF } \\
\hline$(+)$ & 13 (34\%) & $16(42 \%)$ & $20(50 \%)$ & 15 (50\%) & $14(61 \%)$ & 19 (47\%) \\
\hline$(-)$ & $23(61 \%)$ & $22(58 \%)$ & $19(47 \%)$ & $13(43 \%)$ & $8(35 \%)$ & $22(53 \%)$ \\
\hline Indeterminate & $2(5 \%)$ & 0 & $1(3 \%)$ & $2(7 \%)$ & $1(4 \%)$ & 0 \\
\hline \multicolumn{7}{|l|}{$\overline{\mathrm{TST}}$} \\
\hline $10 \mathrm{~mm}(+)$ & $9(24 \%)$ & $14(37 \%)$ & $22(55 \%)$ & $17(57 \%)$ & $13(57 \%)$ & $28(68 \%)$ \\
\hline $5 \mathrm{~mm} \mathrm{(+)}$ & $10(26 \%)$ & $17(45 \%)$ & $24(60 \%)$ & $21(70 \%)$ & $14(61 \%)$ & $33(80 \%)$ \\
\hline
\end{tabular}

Results in rheumatoid arthritis patients before (RA-TNF1) and after (RA-TNF2) treatment with TNF- $\alpha$ antagonists, rheumatoid arthritis patients who were not prescribed TNF- $\alpha$ antagonists (TNF-naive RA), rheumatology patients who had current or past confirmed tuberculosis infection (TB), leprosy patients, and healthy controls. 
Table 2 IFN- $\gamma$ levels in the tuberculosis antigen-stimulated wells and mitogen-stimulated wells that were used as positive controls

\begin{tabular}{lllllll}
\hline & RA-TNF1 $(\boldsymbol{n}=\mathbf{3 8})$ & RA-TNF2 $(\boldsymbol{n}=\mathbf{3 8})$ & $\begin{array}{l}\text { TNF-naive RA } \\
(\boldsymbol{n}=\mathbf{4 0})\end{array}$ & $\begin{array}{l}\text { TB } \\
(\boldsymbol{n}=\mathbf{3 0})\end{array}$ & $\begin{array}{l}\text { Leprosy } \\
(\boldsymbol{n}=\mathbf{2 3})\end{array}$ & Healthy controls $(\boldsymbol{n}=\mathbf{4 1})$ \\
\hline $\begin{array}{l}\text { IFN- } \gamma \text { level in tuberulosis } \\
\text { antigen well }(\mathrm{IU} / \mathrm{ml})\end{array}$ & $3.6 \pm 8.4$ & $3.0 \pm 6.2$ & $2.8 \pm 5$ & $2.3 \pm 4.2$ & $7.3 \pm 8.0$ & $3.5 \pm 6.4$ \\
$\begin{array}{l}\text { IFN- } \gamma \text { level in positive } \\
\text { control well }(\mathrm{IU} / \mathrm{ml})\end{array}$ & $7.0 \pm 6.4$ & $16.1 \pm 14.2^{\mathrm{a}}$ & $8.7 \pm 6.1$ & $11.6 \pm 12.1$ & $12.2 \pm 6.1$ & $17.3 \pm 6.4$ \\
\hline
\end{tabular}

${ }^{a}$ The mitogen-nil level increased significantly $(P<0.001)$ after treatment with TNF- $\alpha$ antagonists.

The frequency of QTF positivity was lowest among TNF-RA patients before starting TNF- $\alpha$ antagonists (34\%); however, the results were not significantly different. The frequency of TST positivity was significantly lower among TNF-RA patients before starting TNF- $\alpha$ antagonists $(24 \%)$ compared with the rest of the groups $(P=0.01)$. The QTF positivity rate was $47 \%$ in healthy controls, whereas the TST positivity rate was $68 \%$.

The IFN- $\gamma$ levels that formed the basis for interpreting the results of the QTF test are given in Table 2. The RA-TNF1 group had the lowest positive control IFN- $\gamma$ level $\left(\mathrm{F}_{5 \mathrm{df}}=7.58 ; P<0.001\right)$ followed by the TNF-naive RA group $\left(\mathrm{F}_{4 \mathrm{df}}=5.15 ; P=0.001\right)$.

Patients with leprosy had a higher mean IFN- $\gamma$ level in the tuberculosis antigen well $(7.3 \pm 8.0 \mathrm{IU} / \mathrm{ml})$ and higher QTF positivity rate (61\%) than the other groups, but the difference was not significant $(P=0.09$ and $P=$ $0.43)$. Their TST positivity rate was not higher than that of the other groups (57\%).

Among rheumatology patients who had had tuberculosis, only two had active, nontreated tuberculosis when blood was collected for the QTF test. The QTF test was positive in one of these patients and indeterminate in the other. Overall, the QTF and TST results of the rheumatology patients who had tuberculosis in the past were similar to those of the TNF-naive RA patients (50\% versus 50\% for QTF and 55\% versus 57\% for TST).

A high discordance rate was found between the QTF test and the TST (Table 3). Among the total 204 valid assays of QTF and TST, 59 (29\%) were discordant, when TST positivity was defined as an induration of $\geq$ $10 \mathrm{~mm}$ (kappa =0.41). We looked at the frequency of BCG vaccination among TST(+) QTF(-) patients to see whether this could explain the discordance in these patients. However, the number of patients with BCG scars among this group was not different from that of the rest of the patients $(23(74 \%)$ of 31 , versus 119 (68\%) of $173 ; P=0.54)$. We had the impression that QTF(+) TST(-) patients had lower IFN- $\gamma$ levels, suggesting that the low cut-off value for positivity might explain the discordance in these patients, but 10 of 28 patients who were QTF positive and TST negative had IFN- $\gamma$ levels below $0.85 \mathrm{IU} / \mathrm{ml}$.

Interobserver reliability for reading the TST was good $($ kappa $=0.95)$. The interobserver reliability of the same two observers was similar in our previous study evaluating TST in patients who were using infliximab (kappa = 0.92) [9].

\section{Discussion}

This study suggested that treatment with TNF- $\alpha$ antagonists does not affect the QTF test. The QTF test was positive in $34 \%$ of the patients before treatment and in $42 \%, 3.6$ months later. It was previously shown that IFN- $\gamma$ production in response to phytohemagglutinin is impaired in RA patients and is more pronounced in RA patients with high inflammatory activity compared with those with low activity $[22,23]$. The fact that the IFN- $\gamma$ level in the positive-control well increased significantly after treatment with TNF- $\alpha$ antagonists, probably because of an improvement in the immunocompromised state of these patients, whereas the IFN- $\gamma$ level in the tuberculosis-antigen well did not change, also supports the notion that results of the QTF test are not affected by treatment with TNF- $\alpha$ antagonists. This is important for showing the utility of this test during treatment with TNF- $\alpha$ antagonists.

Several mechanisms are thought to play roles in the impairment of immunity against tuberculosis in patients

Table 3 Discordance of QTF and TST results in each group, excluding patients with indeterminate QTF results

\begin{tabular}{|c|c|c|c|c|c|c|c|c|}
\hline & & RA-TNF1 $(n=36)$ & RA-TNF2 $(n=38)$ & $\begin{array}{l}\text { TNF-naive RA } \\
(n=39)\end{array}$ & $\begin{array}{l}\text { TB } \\
(n=28)\end{array}$ & $\begin{array}{l}\text { LEPROSY } \\
(n=22)\end{array}$ & Healthy controls $(n=41)$ & $\begin{array}{l}\text { Total } \\
(n=204)\end{array}$ \\
\hline \multirow[t]{2}{*}{ QTF $(+)$} & TST (+) & $5(13 \%)$ & 9 (24\%) & 15 (38\%) & $12(40 \%)$ & 12 (52\%) & 16 (39\%) & 69 (34\%) \\
\hline & TST $(-)$ & $8(21 \%)$ & $7(18 \%)$ & $5(13 \%)$ & $3(10 \%)$ & $2(9 \%)$ & $3(7 \%)$ & $28(14 \%)$ \\
\hline \multirow[t]{2}{*}{ QTF (-) } & TST (+) & $4(11 \%)$ & $5(13 \%)$ & $6(15 \%)$ & $3(10 \%)$ & $1(4 \%)$ & $12(29 \%)$ & $31(15 \%)$ \\
\hline & TST (-) & 19 (50\%) & 17 (45\%) & 13 (33\%) & $10(33 \%)$ & 7 (30\%) & $10(24 \%)$ & $76(36 \%)$ \\
\hline
\end{tabular}

Tuberculin skin test (TST) positivity is defined as an induration of $\geq 10 \mathrm{~mm}$. 
using TNF- $\alpha$ antagonists [24]. One explanation would be that these drugs interfere with the secretion of IFN- $\gamma$ by memory $\mathrm{T}$ cells [24]. This raises concern that IGRAs may not be useful in patients who are already using TNF- $\alpha$ antagonists. An ex vivo study of patients treated with TNF- $\alpha$ antagonists showed that the number of IFN- $\gamma$-releasing lymphocytes and immediate release of IFN $-\gamma$ after challenging with mycobacterial antigens was significantly decreased after 14 weeks of treatment with these drugs, compared with the initial values [25]. The authors concluded that ELISPOT assays are not reliable to diagnose previous or latent tuberculosis in patients using TNF- $\alpha$ antagonists. However, and in line with what we observed here, a clinical study with serial ELISPOT testing before and after treatment with infliximab suggested that ELISPOT is a reliable tool for monitoring tuberculosis in these patients [26]. Similarly, a cross-sectional study that looked at the QTF-Tb Gold test in patients who were already using TNF- $\alpha$ antagonists showed that the number of patients with a positive test was lower in the group treated with TNF- $\alpha$ antagonists and suggested that QTF-Tb Gold positivity decreased with TNF- $\alpha$ antagonist use [27]. However, QTF-Tb Gold assays were not available before treatments with TNF- $\alpha$ antagonists were started in these patients. In contrast, our results provide evidence that the QTF-Tb Gold test is not affected by TNF- $\alpha$ antagonists. Thus it is important to test how IGRAs perform in different immunosuppressed patient populations with serial testing before and after treatment with these agents, especially in settings with a high tuberculosis prevalence.

The lower QTF and TST positivity among RA patients who are prescribed TNF- $\alpha$ antagonists, compared with those who are not, is probably related to the higher disease activity in the first group. The demographic features and the drugs used when the first QTF test was performed were similar between the two groups. However, the first group had a higher disease activity, causing them to be prescribed TNF- $\alpha$ antagonists. A formal analysis of disease activity was not performed for the purposes of this study, but a minimum DAS28 score of 5.1 is required for prescribing TNF- $\alpha$ antagonists in Turkey.

Our study showed that the positivity rate of QTF was higher than the TST among RA patients and lower than the TST in healthy controls. However, because no gold standard exists for diagnosing latent tuberculosis, it is impossible to know definitely which test is more accurate. The QTF test was positive in $47 \%$ of healthy controls, and the TST was positive in $68 \%$. The estimated prevalence of latent tuberculosis, defined as TST positivity among those who did not have a BCG vaccination, is $25 \%$ in Turkey [28]. Thus, assuming that our healthy controls reflect the genreal population in Turkey, we can speculate that the false-positivity rate of QTF may be lower than that of TST, but it is probably still quite high.

Patients with leprosy had the highest QTF positivity rate and mean IFN- $\gamma$ levels in tuberculosis-antigen wells among the groups we studied, whereas their IFN- $\gamma$ levels in positive-control wells and TST positivity rate were not higher than those in the other groups. This finding suggests that the QTF test may give false-positive results in leprosy patients because of cross-sensitivity with $M$. tuberculosis antigens. As far as we know, this is the first study to look at the QTF test in leprosy patients. It may be true that patients with leprosy live in worse socioeconomic conditions, spend more time in hospitals and institutions, and may be more exposed to M. tuberculosis. However, none of the patients we studied had a previous personal history or history of contact with $M$. tuberculosis. Thus it is possible that infection with $M$. leprae might be causing positive QTF results.

The discordance rate between the QTF test and the TST was $29 \%$ in our study. In another study from Turkey, which looked at the agreement between QTF and TST results among RA and AS patients, the QTF was positive among $35 \%$, the TST was positive among $66 \%$ of the patients, and the discordance rate was 39\% [29]. Another study from Turkey, this time among healthcare workers, showed a discordance rate of 37\% [30]. The discordance rate is usually lower in reports from countries where tuberculosis prevalence is low, because most patients are both QTF and TST negative [31]. In countries where tuberculosis is endemic, discordance rates are usually higher [32]. It is suggested that BCG vaccination is one of the reasons for discordance when the TST is positive and the QTF is negative. However, in our population, this was not the case. The number of patients with a BCG scar was similar among TST $(+)$ QTF(-) patients and the rest of the patients. Conversely, $14 \%$ of our patients were QTF(+) and TST(-). These patients usually had low IFN- $\gamma$ levels. This suggests that the current low cut-off value for QTF positivity, as advised by the manufacturer, may be reponsible for some of the QTF(+)TST(-) results, thus increasing the sensitivity, but decreasing the specificity of the test. In our study population, increasing the cut-off for QTF positivity to $0.85 \mathrm{IU} / \mathrm{ml}$ would decrease the frequency of QTF(+)TST(-) discordant results from $14 \%$ to $9 \%$. The problem with the cut-off value was emphasized by another study, which showed that reproducibility is low among patients with IFN- $\gamma$ levels close to the cut-off point [33]. Among patients with inconsistent results between two consecutive tests, maximum IFN- $\gamma$ response in either test was $0.68 \mathrm{IU} / \mathrm{ml}$, compared with $4.99 \mathrm{IU} / \mathrm{ml}$ in persistently positive patients [33]. Thus, it is important to interpret QTF results, not just as 
negative or positive, but quantitatively, together with IFN- $\gamma$ levels in the positive-control and tuberculosisantigen wells, especially in immunosuppressed populations.

We had only two rheumatology patients with active tuberculosis at the time of this study. The other patients who had had tuberculosis in the past had received sufficient antituberculosis treatment. This may be the reason for the low QTF positivity in this group. However, QTF positivity rates of as low as $64 \%$ have previously been reported among patients with active tuberculosis [34].

The main limitation of our study is the same with all QTF and, for that matter, TST studies. No gold standard exists for diagnosing latent tuberculosis. In most studies about the sensitivity of the QTF test for latent tuberculosis, surrogates (such as history of exposure to a patient with tuberculosis, sequelae on chest radiograph, or active tuberculosis) have been used [10]. Because of this uncertainty, we did not attempt to calculate sensitivities and specificities of the QTF and TST tests. We compared the results of patient groups with healthy controls instead.

The other limitation of our study was that it lacked long-term follow-up. Although the prospective nature of our study among patients using TNF- $\alpha$ antagonists gave us an idea about the effect of anti-TNF treatment on the QTF test, we do not know whether being QTF positive shows a risk for activation of latent tuberculosis in the long term. In our limited experience, we can point out that among the eight patients who were QTF positive and TST negative initially, and who did not use isoniazid, none has developed tuberculosis. It is reasonable to postulate that these same patients would be expected to develop activation within the first few months of TNF- $\alpha$ antagonists use, had they had latent tuberculosis. However, data on more patients are needed to comment on the safety of not treating such patients, as well as patients who had QTF conversion from negative to positive during treatment with TNF- $\alpha$ antagonists.

When considering QTF as a means for screening latent tuberculosis in large populations, it has advantages, such as the lack of boosting and no need for return visits, but it also has several problems. It is expensive and requires specialized laboratories. Its positivity rate in other mycobacteria and its reproducibility and reliability must be studied further in immunocompromised populations.

Previous studies comparing QTF and TST for screening latent tuberculosis before starting TNF- $\alpha$ antagonists suggested that these tests show good concordance in populations with low tuberculosis prevalence [35]. In such settings, the QTF test may be used either to confirm positive TST results or when false-negative TST results are suspected [12].

\section{Conclusions}

In conclusion, the QTF test does not seem to be affected by TNF- $\alpha$ antagonists. In terms of screening patients for latent tuberculosis before starting TNF- $\alpha$ antagonists, no convincing data favor the QTF test or the TST. Moreover, considering feasibility and costeffectiveness, it is hard to recommend the routine use of QTF test for screening latent tuberculosis before treatment with TNF- $\alpha$ antagonists in countries with a high prevalence of tuberculosis. The frequency of reactivation of tuberculosis during anti-TNF therapy has significantly decreased with routine screening before starting treatment [36]. However, this decrease seems to be related to increased clinical and radiologic awareness rather than to the QTF or the TST. This is further supported by the observation that, in a large series of validated tuberculosis cases among patients using TNF- $\alpha$ antagonists, initial TST was negative in $67 \%$ of the patients [37].

\section{Abbreviations}

BCG: Bacille Calmette-Guérin; HC: healthy control; IFN- $\gamma$ : interferon gamma; IGRA: interferon gamma release assay; QTF: Quantiferon-TB Gold in-tube assay; RA: rheumatoid arthritis; TNF-a: tumor necrosis factor alpha; TNF-naive RA: RA patients who had not used and who were not being considered for using TNF-a antagonists; TNF-RA: RA patients who were about to start treatment with TNF-a antagonists; TST: tuberculin skin test.

\section{Acknowledgements}

The authors thank the study nurse Mine Batumlu for her help in collection and preparation of the samples and the tuberculin skin test, and Dr Ozlem Can, for her help with the recruitment of leprosy patients.

\section{Author details}

${ }^{1}$ Istanbul University, Cerrahpasa Medical School, Department of Internal Medicine, Division of Rheumatology, Istanbul, Turkey. ${ }^{2}$ Istanbul University, Cerrahpasa Medical School, Central Laboratory, Istanbul, Turkey.

\section{Authors' contributions}

$\mathrm{GH}$ contributed in designing the study, collected and analyzed data, and drafted the manuscript. MM contributed in designing the study, collection of data, and drafting of the manuscript. FB performed the laboratory analyses. KT contributed in collection of data. HY contributed in designing the study, analysis of data, and drafting of the manuscript. All authors read and approved the manuscript.

\section{Competing interests}

The authors declare that they have no competing interests.

Received: 16 November 2011 Revised: 12 April 2012

Accepted: 18 June 2012 Published: 18 June 2012

\section{References}

1. Gómez-Reino JJ, Carmona L, Valverde VR, Mola EM, Montero MD, BIOBADASER Group: Treatment of rheumatoid arthritis with tumor necrosis factor inhibitors may predispose to significant increase in tuberculosis risk: a multicenter active-surveillance report. Arthritis Rheum 2003, 48:2122-2127.

2. Koike R, Takeuchi T, Eguchi K, Miyasaka N, Japan College of Rheumatology: Update on the Japanese guidelines for the use of infliximab and etanercept in rheumatoid arthritis. Mod Rheumatol 2007, 17:451-458.

3. Elkayam O, Balbir-Gurman A, Lidgi M, Rahav G, Weiler-Ravel D: Guidelines of the Israeli association of rheumatology for the prevention of 
tuberculosis in patients treated with TNF-a blockers. Harefuah 2007, 146:235-237, 244.

4. Furst DE, Breedveld FC, Kalden JR, Smolen JS, Burmester GR, Sieper J, Emery P, Keystone EC, Schiff MH, Mease P, van Riel PL, Fleischmann R Weisman MH, Weinblatt ME: Updated consensus statement on biological agents for the treatment of rheumatic diseases, 2007. Ann Rheum Dis 2007, 66(Suppl 3):iii2-iii22.

5. Centers for Disease Control and Prevention (CDC): Tuberculosis associated with blocking agents against tumor necrosis factor-alpha: California, 2002-2003. MMWR Morb Mortal Wkly Rep 2004, 53:683-686.

6. Ding T, Ledingham J, Luqmani R, Westlake $S$, Hyrich $K$, Lunt $M$, Kiely $P$, Bukhari M, Abernethy R, Bosworth A, Ostor A, Gadsby K, McKenna F, Finney D, Dixey J, Deighton C, Audit and Guidelines Working Group of BSR Clinical Affairs Committee: BHPR: BSR and BHPR rheumatoid arthritis guidelines on safety of anti-TNF therapies. Rheumatology (Oxford) 2010, 49:2217-2219.

7. Mariette $X$, Salmon D: French guidelines for diagnosis and treating latent and active tuberculosis in patients with RA treated with TNF blockers. Ann Rheum Dis 2003, 62:791.

8. Keystone EC, Papp KA, Wobeser W: Challenges in diagnosing latent tuberculosis infection in patients treated with tumor necrosis factor antagonists. J Rheumatol 2011, 38:1234-1243.

9. Hatemi G, Melikoglu M, Fresko I, Masatlioglu S, Tascilar K, Yazici H: Infliximab does not suppress the tuberculin skin test (purified protein derivative). J Rheumatol 2007, 34:474-480

10. Menzies D, Pai M, Comstock G: Meta-analysis: new tests for the diagnosis of latent tuberculosis infection: areas of uncertainty and recommendations for research. Ann Intern Med 2007, 146:340-354.

11. Ponce de Leon D, Acevedo-Vasquez E, Alvizuri S, Gutierrez C, Cucho M, Alfaro J, Perich R, Sanchez-Torres A, Pastor C, Sanchez-Schwartz C, Medina M, Gamboa R, Ugarte M: Comparison of an interferon-gamma assay with tuberculin skin testing for detection of tuberculosis (TB) infection in patients with rheumatoid arthritis in a TB-endemic population. J Rheumatol 2008, 35:776-781.

12. Bocchino M, Matarese A, Bellofiore B, Giacomelli P, Santoro G, Balato N, Castiglione F, Scarpa R, Perna F, Signoriello G, Galati D, Ponticiello A, Sanduzzi A: Performance of two commercial blood IFN-gamma release assays for the detection of Mycobacterium tuberculosis infection in patient candidates for anti-TNF-alpha treatment. Eur I Clin Microbiol Infect Dis 2008, 27:907-913.

13. Chen DY, Shen GH, Hsieh TY, Hsieh CW, Lan JL: Effectiveness of the combination of a whole-blood interferon-gamma assay and the tuberculin skin test in detecting latent tuberculosis infection in rheumatoid arthritis patients receiving adalimumab therapy. Arthritis Rheum 2008, 59:800-806.

14. Chen DY, Shen GH, Hsieh TY, Hsieh CW, Lan JL: Comparison of an in vitro tuberculosis interferon-gamma assay with delayed-type hypersensitivity testing for detection of latent Mycobacterium tuberculosis: a pilot study in rheumatoid arthritis. J Rheumatol 2008, 35:770-775.

15. Kaushik W, Ambalavanan S, Binymin K: Comment on: Use of the QuantiFERON TB Gold test as part of a screening programme in patients with RA under consideration for treatment with anti-TNF-alpha agents: the Newcastle (UK) experience. Rheumatology (Oxford) 2007, 46:1863-1864.

16. Lalvani A, Millington KA: Screening for tuberculosis infection prior to initiation of anti-TNF therapy. Autoimmun Rev 2008, 8:147-152.

17. Geluk A, van Meijgaarden KE, Franken KL, Wieles B, Arend SM, Faber WR, Naafs B, Ottenhoff TH: Immunological crossreactivity of the Mycobacterium leprae CFP-10 with its homologue in Mycobacterium tuberculosis. Scand I Immunol 2004, 59:66-70.

18. Vilela Lopes R, Barros Ohashi C, Helena Cavaleiro L, de Britto Pereira Cruz R, da Veiga RR, Fernando Ribeiro Miranda M, Toshimitsu Yoshikawa G: Development of leprosy in a patient with ankylosing spondylitis during the infliximab treatment: reactivation of a latent infection? Clin Rheumatol 2009, 28:615-617.

19. Scollard DM, Joyce MP, Gillis TP: Development of leprosy and type 1 leprosy reactions after treatment with infliximab: a report of 2 cases. Clin Infect Dis 2006, 43:e19-e22

20. Oberstein EM, Kromo O, Tozman EC: Type I reaction of Hansen's disease with exposure to adalimumab: a case report. Arthritis Rheum 2008, 59:1040-1043.
21. Nestorov I: Clinical pharmacokinetics of TNF antagonists: how do they differ? Semin Arthritis Rheum 2005, 34(Suppl 1):12-8.

22. Stolzenburg T, Binz H, Fontana A, Felder M, Wagenhaeuser FJ: Impaired mitogen-induced interferon-gamma production in rheumatoid arthritis and related diseases. Scand J Immunol 1988, 27:73-81.

23. Seitz M, Napierski I, Augustin R, Hunstein W, Kirchner H: Reduced production of interferon alpha and interferon gamma in leukocyte cultures from patients with active rheumatoid arthritis. Scand J Rheumatol 1987, 16:257-262.

24. Harris J, Keane J: How tumor necrosis factor blockers interfere with tuberculosis immunity. Clin Exp Immunol 2010, 161:1-9.

25. Hamdi H, Mariette X, Godot V, Weldingh $\mathrm{K}$, Hamid AM, Prejean MV Baron G, Lemann M, Puechal X, Breban M, Berenbaum F, Delchier JC, Flipo RM, Dautzenberg B, Salmon D, Humbert M, Emilie D, RATIO (Recherche sur Anti-TNF et Infections Opportunistes) Study Group: Inhibition of anti-tuberculosis T-lymphocyte function with tumour necrosis factor antagonists. Arthritis Res Ther 2006, 8:R114.

26. Xie X, Chen JW, Li F, Tian J, Gao JS, Zhang D: A T-cell-based enzymelinked immunospot assay for tuberculosis screening in Chinese patients with rheumatic diseases receiving infliximab therapy. Clin Exp Med 2011, 11:155-161.

27. Matulis G, Jüni P, Villiger PM, Gadola SD: Detection of latent tuberculosis in immunosuppressed patients with autoimmune diseases: performance of a Mycobacterium tuberculosis antigen-specific interferon gamma assay. Ann Rheum Dis 2008, 67:84-90.

28. Verem Savaşi Daire Başkanliği: Türkiye'de Tüberkülozun Kontrolü İ̧in Başvuru Kitabi, Ankara 2003.

29. Inanc N, Aydin SZ, Karakurt S, Atagunduz P, Yavuz S, Direskeneli H: Agreement between Quantiferon-TB gold test and tuberculin skin test in the identification of latent tuberculosis infection in patients with8 rheumatoid arthritis and ankylosing spondylitis. J Rheumatol 2009, 36:2675-2671.

30. Ozdemir D, Annakkaya AN, Tarhan G, Sencan I, Cesur S, Balbay O, Guclu E: Comparison of the tuberculin skin test and the quantiferon test for latent Mycobacterium tuberculosis infections in health care workers in Turkey. Jpn J Infect Dis 2007, 60:102-105.

31. Nienhaus A, Schablon A, Diel R: Interferon-gamma release assay for the diagnosis of latent TB infection: analysis of discordant results, when compared to the tuberculin skin test. PLoS One 2008, 3:e2665.

32. Mahomed H, Hughes EJ, Hawkridge T, Minnies D, Simon E, Little F, Hanekom WA, Geiter L, Hussey GD: Comparison of mantoux skin test with three generations of a whole blood IFN-gamma assay for tuberculosis infection. Int I Tuberc Lung Dis 2006, 10:310-316.

33. Hesseling AC, Mandalakas AM, Kirchner HL, Chegou NN, Marais BJ, Stanley K, Zhu X, Black G, Beyers N, Walzl G: Highly discordant T cell responses in individuals with recent exposure to household tuberculosis. Thorax 2009, 64:840-846.

34. Dewan PK, Grinsdale J, Kawamura LM: Low sensitivity of a whole-blood interferon-gamma release assay for detection of active tuberculosis. Clin Infect Dis 2007, 44:69-73.

35. Perry S, Sanchez L, Yang S, Agarwal Z, Hurst P, Parsonnet J: Reproducibility of QuantiFERON-TB gold in-tube assay. Clin Vaccine Immunol 2008, 15:425-432.

36. Carmona L, Gómez-Reino JJ, Rodríguez-Valverde V, Montero D, PascualGómez E, Mola EM, Carreño L, Figueroa M, BIOBADASER Group: Effectiveness of recommendations to prevent reactivation of latent tuberculosis infection in patients treated with tumor necrosis factor antagonists. Arthritis Rheum 2005, 52:1766-1772.

37. Tubach F, Salmon D, Ravaud P, Allanore Y, Goupille P, Bréban M, Bréban M, Pallot-Prades B, Pouplin S, Sacchi A, Chichemanian RM, Bretagne S, Emilie D, Lemann M, Lortholary O, Mariette X, Research Axed on Tolerance of Biotherapies Group: Risk of tuberculosis is higher with anti-tumor necrosis factor monoclonal antibody therapy than with soluble tumor necrosis factor receptor therapy: the three-year prospective French Research Axed on Tolerance of Biotherapies registry. Arthritis Rheum 2009, 60:1884-1894.

\section{doi:10.1186/ar3882}

Cite this article as: Hatemi et al:: Quantiferon-TB Gold in tube assay for the screening of tuberculosis before and during treatment with tumor necrosis factor alpha antagonists. Arthritis Research \& Therapy 201214 R147. 